\title{
A inserção da inovação em pequenos empreendimentos hoteleiros na cidade de Aracaju/SE: um estudo de múltiplos casos
}

Adrianne Garcia Corrêa Silva ${ }^{1}$

Magno Willams De Macêdo Farias ${ }^{1}$

Débora Eleonora Pereira Da Silva ${ }^{1}$

Aline França De Abreu ${ }^{1}$

${ }^{1}$ Programa de Mestrado Acadêmico em Administração da Universidade Federal de Sergipe 


\section{A INSERÇÃO DA INOVAÇÃO EM PEQUENOS EMPREENDIMENTOS HOTELEIROS NA CIDADE DE ARACAJU/SE: UM ESTUDO DE MÚLTIPLOS CASOS}

Resumo: A acirrada concorrência entre as empresas do setor turístico tem impulsionado a inserção de novas tecnologias, novos serviços, melhoria da qualidade, marketing, adoção de medidas sustentáveis, entre outras ferramentas, de forma a sustentar uma vantagem competitiva frente aos seus concorrentes. O objetivo desse artigo é analisar a percepção do pequeno empreendedor sobre a inserção da ferramenta da inovação em seu empreendimento. A metodologia empregada propõe uma abordagem qualitativa de natureza descritiva e exploratória sobre o tema em análise. Foi feita a escolha por um estudo de casos múltiplos com três empresas do ramo hoteleiro da cidade de Aracaju. A conclusão que se chega nesse estudo é de que, em teoria, os empreendedores entendem como importante a constante mudança no sentido de inovar, e de principalmente estar atentos aos comentários de clientes nesse processo, que se torna um fator crítico para essa mudança, porém, na prática, existem fatores em seu discurso que enfraquecem essa teoria.

Palavras-chave: Inovação. Turismo. Setor turístico. Empreendedorismo. 


\section{Introdução}

Segundo dados do UNWTO Tourism Highlights (2016), o turismo é uma das principais categorias de comércio internacional de serviços. Além de receitas recebidas em destinos, o turismo internacional também gerou 211 bilhões de dólares em exportações por meio de serviços internacionais de transporte de passageiros prestados a não residentes em 2015, elevando o valor total das exportações até 1,5 trilhão de dólares ou 4 bilhões de dólares por dia, em média. O turismo internacional representa hoje $7 \%$ das exportações mundiais de em comparação com 6\% em 2014. Como categoria de exportação mundial, o turismo ocupa o terceiro lugar. Em muitos países em desenvolvimento, o turismo é o primeiro setor de exportação.

O setor turístico brasileiro é um grande impulsionador da indústria automobilística, gastronômica, artesanal, entre outras, sendo responsável por 3,7\% do PIB nacional, empregando cerca de 10 milhões de pessoas (Ministério do Turismo, 2015). Devido a globalização econômica, a abertura dos mercados, entre outros fatores, a concorrência no setor turísticos não é apenas local ou regional, mas global, de forma que os gestores de empresas precisam estar atentos aos desafios fruto dessa competição (PETROCCHI, 2009; JO ̃̃O et al., 2011).

No ramo hoteleiro, a pesquisa realizada pela HotelInvest - HVS (2014) previu uma travessia turbulenta no ano 2015- seguindo para um cenário mais tranquilo a médio prazo. Segundo Petrocchi (2002), os hotéis deixaram de ser apenas dormitórios, agregando em sua estrutura física espaços de convivência para eventos, seguindo novas tendências de mercado, correspondendo às demandas do mercado, uma vez que a inovação não se configura apenas como mero diferencial, mas como um fator essencial para a sobrevivência da empresa (BESSANT; TIDD, 2009). Bruyat e Julian (2000) sugerem que o empreender tem um papel fundamental na criação de uma inovação, de forma que sem a sua participação, este processo pode não acontecer.

No Brasil, cerca de $75 \%$ das empresas são familiares - e esse percentual pode subir se levado em consideração apenas o número referente a pequenos empreendimentos responsáveis por cerca de $50 \%$ do PIB interno e $60 \%$ dos postos de trabalho (LARA DE OLIVEIRA; PEREIRA, ALBUQUERQUE, 2012; NÓBREGA; HOFFMANN, 2014). As empresas familiares tendem ser mais resistentes no processo de inovação (MELÉNDEZ, SOTO, MORENO, 2015).

O Estado de Sergipe conta com aproximadamente 264 estabelecimentos de hospedagem entre hotéis e pousadas, 7.131 unidades habitacionais e 14.027 leitos, segundo dados de 2014 da Secretaria de Estado do Planejamento, Orçamento e Gestão, porém, quando esse número é confrontado com os dados do Ministério do Turismo, percebe-se que apenas 49 estabelecimentos hoteleiros estão cadastrados pelo Ministério do Turismo, 3.350 unidades habitacionais e 6.676 leitos.

Os meses de junho a janeiro tornaram-se um período de grande fluxo turístico em Sergipe. Por conta das férias de final de ano e dos tradicionais festejos juninos, os hotéis garantem uma média de ocupação que varia de $80 \%$ a $90 \%$, segundo a ABIH/SE. Em média, acredita-se que a taxa de ocupação hoteleira é de 61,1\%. A EMSETUR desenvolve periodicamente capacitações e reciclagens com camareiras, recepcionistas, garçons, taxistas, e
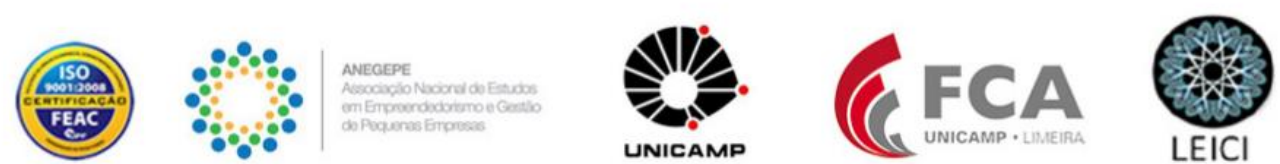
demais profissionais que compõem o ramo turístico, porém é necessário a consciência do próprio empreendedor sobre inovações que necessitam ser feitas em seu estabelecimento, garantindo maior atratividade por meio da gestão da inovação.

Diante do exposto, esse trabalho visa contribuir com as pesquisas em gestão da inovação em pequenos empreendimentos hoteleiros, visto que a literatura ainda é incipiente no tocante a abordagem da percepção do empreendedor sobre a inserção dessa ferramenta em seu empreendimento (TORRES, SILVA; 2014; SALES; SANCHES, 2013;). Dessa forma, o objetivo desse artigo é analisar a percepção do pequeno empreendedor sobre a inserção da ferramenta da inovação em seu empreendimento. A metodologia empregada propõe uma abordagem qualitativa de natureza descritiva e exploratória sobre o tema em análise. Foi feita a escolha por um estudo de casos múltiplos com três empresas do ramo hoteleiro da cidade de Aracaju.

O artigo apresenta-se estruturado da seguinte maneira: revisão da literatura dividida dois tópicos: Inovação em Turismo e Inovação em pequenos empreendimentos, seguindo para o detalhamento dos procedimentos metodológicos. Em seguida, será realizada caracterização das empresas estudadas, junto a análise dos dados coletados, finalizando com as conclusões baseadas na análise dos dados coletados e sugestões para pesquisas futuras.

\section{Inovação no setor turístico}

A acirrada concorrência entre as empresas do setor turístico tem impulsionado a inserção de novas tecnologias, novos serviços, melhoria da qualidade, marketing, adoção de medidas sustentáveis, entre outras ferramentas, de forma a sustentar uma vantagem competitiva frente aos seus concorrentes (FIRMINO, 2007; RUSCHMANN; SOLHA, 2003; SACRAMENTO; TEIXEIRA, 2014). Segundo Cardoso e Batista (2013), por ser o turismo uma atividade vulnerável à dinâmica da globalização, que tem afetado a tendência e as preferências dos consumidores, caracteriza-se por uma constante mudança nas necessidades dos consumidores no que diz respeito a competitividade, economia e tecnologia.

As empresas que têm a capacidade de enxergar e ultrapassar esses desafios são capazes de se manter no mercado, utilizando uma ferramenta que passa a ser essencial nesse cenário: a inovação (CARDOSO; BATISTA, 2013). Smith, Busi, Ball e Meer (2008), argumentam sobre necessidade que as empresas têm de aumentarem a sua capacidade de inovação para que se mantenham competitivas no mercado. De acordo com Pavitt (1984), o conceito de inovação está ligado ao sucesso de um produto ou processo produtivo ou sua comercialização. Concordam com esse pensamento Damanpour e Shneider (2006), que sugerem que a capacidade de inovar é dependente, entre outros fatores, da capacidade de absorção da informação e de uma cultura organizacional que promova capacidades organizacionais e estratégicas para pôr em prática ideias e métodos diferentes, gerando assim novos produtos e processos inovadores.

O conceito de inovação ainda é bastante contraditório entre os autores. Para Tidd, Bessant e Pavitt (2005, p.86) "A inovação é um processo de fazer de uma oportunidade uma nova ideia e de colocá-la em uso da maneira mais ampla possível" (TIDD; BESSANI; PAVITT, 2005, p. 86). O Manual de Oslo (2004) traz quatro tipos de inovação: inovação em produtos, inovação de processos, inovações organizacionais e inovações em marketing. $\mathrm{O}$ conceito adotado nesse artigo foi o de Rogers (1983), que percebe a inovação como uma

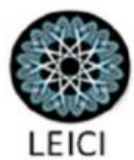


ideia, prática ou objeto percebido como novo por um indivíduo ou por uma unidade de adoção.

Segundo Alves (2011), as inovações no setor de hotelaria concentram-se majoritariamente nas estratégias de liderança em custo e foco de mercado e serviços. A maior parte da indústria hoteleira no Brasil é formada por hotéis independentes, chegando a aproximadamente $70 \%$ da rede hoteleira nacional em 2004 (VALOR ECONÔMICO, 2006). A estratégias de liderança em custo e foco de mercado e serviços justifica-se pelo fato de que são estratégias mais simples de serem administradas por pequenas empresas. Yu e Klement (2006), em um estudo bibliográfico sobre inovação em serviços e na indústria hoteleira, constatam o crescimento em inovação tecnológica por empresas do ramo de hotelaria, sobretudo na adesão de parcerias com websites para reserva de unidades habitacionais e gestão de informações.

A atividade de inovação no setor turístico, sobretudo no ramo hoteleiro, está relacionada à inovação em serviços. Segundo Mattson, Sundbo e Jensen (2005), o investimento em inovação no setor turístico pode representar uma desvantagem em relação a outras pelo fato de contar com inovações de fácil imitação e de baixo nível tecnológico. Dessa forma, torna-se um fator ainda mais crítico para as empresas no ramo turístico manterem-se atentas e atualizadas diante as mudanças cotidianas.

\section{Inovação em pequenos empreendimentos}

O empreendedorismo é um campo de estudo que ainda procura por seu espaço dentro da academia e, historicamente, tem tido limitada exposição em revistas e jornais de grande influência, segundo Busetnitz et al (2014), uma vez que não prevê fenômenos empíricos além dos que já se conhece e que são provenientes de outros campos (SHANE e VENTAKARAMAN, 2000). Todavia, para Landstrom, Hirirchi e Astrom (2012), esta situação se modificou com um aumento significativo de pesquisas nesta área nas últimas duas décadas, algo que demonstra a evolução do interesse da academia sobre o tema referente ao empreendedorismo. Para Busenitz et al (2014, p. 983), o empreendedorismo é um campo de estudo "interdisciplinar onde uma variedade de perspectivas teóricas são usadas como um guia para sondar fenômenos empreendedores", mas ainda é um campo à procura de sua própria maturidade.

De acordo com os autores, na última década o empreendedorismo apresentou um crescimento do interesse e da popularidade do campo atraindo diversos pesquisadores que passaram a desenvolver suas pesquisas relacionando o empreendedorismo à várias disciplinas acabando por compor uma heterogeneidade para este campo de pesquisa.

Existem várias classificações de empresas por seu porte de acordo com número de funcionários ou faturamento, por exemplo (FROES, 2008). O critério utilizado por este trabalho será o critério do SEBRAE (2013): (1) Micro empresa - até 19 empregados; (2) Pequena empresa - de 20 a 99 empregados; (3) Média empresa - de 100 a 499 empregados; (4) Grande empresa - mais de 500 empregados. De acordo com o BNDES (2014), microempresa é aquela com faturamento anual menor ou igual a $\mathrm{R} \$ 2,4$ milhões.

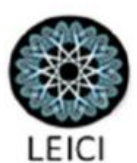


Froes (2008) esclarece que na maioria das pequenas e microempresas não existe a cultura de gestão e planejamento estratégicos para desenvolvimento do negócio, nem mesmo grandes capacidades inovadoras, dificultando a sobrevivência dessas organizações. Muitas vezes, essas empresas são geridas de forma amadora, trazendo em sua gestão apenas a percepção e as vontades do seu gerente-proprietário.

Lara de Oliveira, Albuquerque e Pereira (2012) sugerem que $75 \%$ das empresas brasileiras são gerenciadas por famílias. A definição de empresas familiares trazida por Chua et al. (1999) é a seguinte: empresas cuja visão é desenvolvida aliança familiar dominante ou um pequeno grupo de famílias que é sustentada ao longo de gerações. Estudos recentes encontraram evidências sobre o efeito da influência da família nos resultados em inovação (Classen et al., 2014; De Massis et al.,2015; Matzler et al., 2015).

Dentro da indústria hoteleira também existem evidências de que a maior parte de hotéis no país são de origem familiar. Alves (2011) afirma que os empreendimentos hoteleiros no Brasil podem ser divididos em três grupos distintos: (1) Hotéis independentes: grupo formado principalmente pelas empresas de gestão familiar tradicional, em geral de pequeno porte e representando o grupo de maior número de estabelecimentos no país - 70\% do total em 2004 (Valor Econômico, 2006); (2) Redes hoteleiras de capital nacional; e (3) Grandes grupos de turismo que incluem as redes hoteleiras internacionais.

Em um estudo sobre inovação nas empresas de Caruaru, Torres (2014) constatou que as três maiores barreiras para a inserção da inovação em pequenos empreendimentos são: alto custo, falta de pessoal qualificado e prazo de retorno a longo prazo. Dada a alta concorrência em todos os setores da indústria do turismo, as microempresas precisam desenvolver ferramentas de inovação, não só para acompanhar as tendências que vêm sendo inseridas pela globalização, mas para gerar uma vantagem competitiva que sustente a sua sobrevivência a longo prazo.

\section{Metodologia}

A metodologia empregada neste artigo propõe uma abordagem qualitativa de natureza descritiva e exploratória sobre o tema em análise, tendo em vista que há poucas pesquisas desenvolvidas sob a ótica proposta (NEUMAN, 1997). Devido a escolha de uma temática relativamente nova como objeto de análise, optou-se por escolher o método de estudo de casos múltiplos que, de acordo com Yin (2015), apresenta-se como uma escolha adequada para análises que não necessitam controle sobre eventos comportamentais. Além disso, aplicase a estudos que exploram situações em que não há um único e claro conjunto de resultados (YIN, 2015). A pesquisa apresenta a estratégia de estudo de casos múltiplos, terminologia adotada por Yin (2015), que sugere resultados mais robustos e globais utilizando múltiplos casos. Dessa forma, é possível reproduzir resultados que se assemelham - uma forma de replicação literal. A técnica de coleta de dados utilizada foi a de entrevistas semiestruturadas. As entrevistas semiestruturadas seguem um roteiro pré-definido pelo pesquisador, que ao mesmo tempo possui a liberdade de inserir questões no decorrer da entrevista (BERG, 2001). Segundo Yin (2015) tem como ponto forte o foco direto nos tópicos do estudo de caso, também fornecendo explicações e visões pessoais (percepções, atitudes e significados).
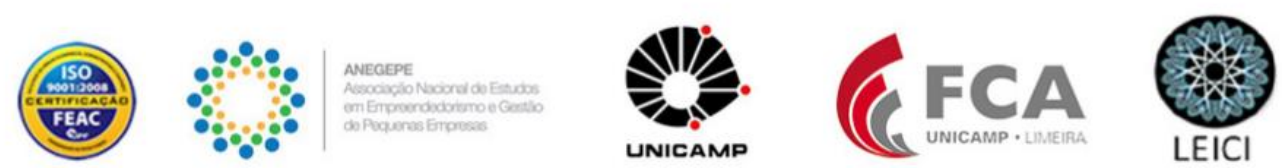
O critério de escolha das empresas baseou-se em conveniência, por parte do pesquisador, atendendo aos seguintes itens:

a) Hotel ou pousada localizada na cidade de Aracaju;

b) Com pelo menos cinco funcionários ativos;

c) Que esteja no mercado há, pelo menos, cinco anos.

$\mathrm{O}$ critério "a" se justifica pela conveniência relacionada à proximidade e a consequente acessibilidade de tais empresas por parte dos pesquisadores. Outra justificativa, para tal critério, se dá pela maior facilidade de os pesquisadores possuírem em suas relações pessoais contatos com pessoas ou empresas que estabeleçam uma porta de entrada para que ocorra uma busca de informação.

O critério " $b$ " se baseia no tamanho da empresa, de forma que seja possível garantir a existência de possíveis funcionários que possam auxiliar com ideias e conhecimento o processo de inovação, bem como caracterizar a empresa segundo o porte sugerido pelo SEBRAE (2013). O objetivo é eliminar a possibilidade de o empreendedor alegar que não só existe a sua pessoa para todas as atividades, de forma que não tem a possibilidade de investir em inovação.

O critério "c" foi adotado tendo em vista que, segundo o SEBRAE (2013), 31,8\% das empresas formais não sobrevivem por um período maior que dois anos no município de Aracaju. Dessa forma, essas empresas encontram-se consolidadas no mercado. Ainda que tal critério não se encontre embasado e, ao mesmo tempo, se apresente de forma frágil, segundo Yin (2001), quando os limites entre o fenômeno e o contexto não estão claramente definidos, o estudo de caso se apresenta como um método que permite, deliberadamente, que as condições contextuais sejam permeadas por escolhas feitas com a crença de que estas possam ser altamente pertinentes ao fenômeno de estudo.

As entrevistas foram gravadas e posteriormente transcritas para serem feitas suas análises de conteúdo. Segundo Laville e Dionne (1999), a análise de conteúdo permite abordar uma grande diversidade de objetos de investigação, tais como: atitudes, valores, representações, mentalidades, ideologias, entre outros.

Foram entrevistados três empreendedores de hotéis e pousadas localizadas na zona hoteleira de Aracaju. As entrevistas foram feitas no próprio estabelecimento e duraram cerca de quarenta minutos. Os proprietários das empresas se disponibilizaram a apresentar os aposentos dos hotéis, auxiliando a percepção dos pesquisadores sobre a estrutura dos estabelecimentos.

Com a finalidade de atender o objetivo do artigo, o roteiro de entrevistas foi baseado nas seguintes categorias de análise:

Quadro 01 - Categorias e elementos de análise

\begin{tabular}{|c|c|}
\hline Categorias de análise & Elementos de análise \\
\hline Perfil do empreendimento & $\begin{array}{c}\text { Histórico, localização, tempo de existência, } \\
\text { estrutura física e organizacional, média de ocupação, } \\
\text { principais clientes. }\end{array}$ \\
\hline Perfil do empreendedor & $\begin{array}{c}\text { Idade, sexo, escolaridade, como acontece a } \\
\text { tomada de decisão. }\end{array}$ \\
\hline
\end{tabular}




\begin{tabular}{|c|c|}
\hline $\begin{array}{l}\text { Percepção sobre a importância da } \\
\text { lovação }\end{array}$ & $\begin{array}{l}\text { Importância dada a inovação, implantação de } \\
\text { sugestões, interesse em buscar novidades sobre o ramo } \\
\text { em outras fontes, disposição em investir } \\
\text { financeiramente. }\end{array}$ \\
\hline Inovações no empreendimento & $\begin{array}{l}\text { Práticas adotadas consideradas como inovação } \\
\text { pelo empreendedor. }\end{array}$ \\
\hline
\end{tabular}

Fonte: elaborado pelos autores (2017).

\section{Descrição e análise de dados}

Nesta seção será feita a descrição dos casos selecionados, seguidos da análise do conteúdo disponibilizado na pesquisa, fazendo uma comparação com estudos na literatura. As categorias analíticas apresentadas no quadro 01 serviram de base para o roteiro de entrevista. Para resguardar o sigilo das fontes, os nomes dos estabelecimentos, bem como dos proprietários entrevistados foram substituídos por nomes fictícios.

\section{Caso 01: Hotel Maresia}

O Hotel Maresia, localizado no bairro Atalaia, foi fundado em 1999 pelo sr. Herman Lírio, engenheiro civil, que optou por empreender como uma forma de preencher seu tempo livre, bem como complementar sua renda. O hotel é um empreendimento de pequeno porte, conforme critério do SEBRAE (2013), contando com nove (09) empregados, com funcionamento 24 horas, vinte e cinco (25) unidades habitacionais divididas em quartos duplos, triplos, quádruplos e quíntuplos, sendo esta última categoria considerada rara em estabelecimentos hoteleiros na cidade. Todas as unidades são equipadas com TV a cabo, WiFi gratuito, telefone, frigobar, ducha quente e secadores nos respectivos banheiros privativos. Também possui cozinha para fornecimento de refeição (café da manhã) e estacionamento gratuito.

Quanto à média de ocupação, o proprietário afirmou que em baixa temporada a ocupação fica em torno de $40 \%$ das unidades habitacionais, e em alta temporada chega a $80 \%$, sendo seus principais clientes os corporativos, mantendo a maior parte da ocupação do hotel ao longo do ano. O sr. Herman considera três como sendo os pontos fortes do seu estabelecimento: o café da manhã que, segundo seu relato, é bastante elogiado pela clientela, o atendimento, também bastante elogiado, principalmente no Booking, e o conforto, tendo em vista o tamanho dos quartos e os itens pertencentes a eles.

Quanto aos principais concorrentes, foram o proprietário citou os hotéis Sandrin, Simas e San Manoel, localizados na avenida principal da Orla de Aracaju/SE e com estrutura superior ao seu estabelecimento, mas que competem em relação ao custo, conforme estudo de Alves (2011).

Quanto à estrutura organizacional, o Hotel Maresia não possui estrutura formalmente organizada, sendo, na prática, o seu proprietário o gerente administrativo-financeiro e todos os outros empregados estando abaixo dessa posição e em um mesmo nível hierárquico. Observou-se que a filha do proprietário, que possui carteira assinada como recepcionista, estando no mesmo nível hierárquico que os outros empregados, faz as vezes de gerente, principalmente quando o seu pai não está presente. Dessa forma, percebe-se uma forte

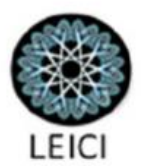


influência familiar dentro da empresa: apesar de formalmente a filha do dono ser uma empregada que está no mesmo patamar que os demais, na prática isso não acontece. De Vries (1993) aponta em seu estudo que uma das desvantagens das empresas familiares é que elas sofrem um certo grau de nepotismo: membros da família que não possuem competências necessárias podem ocupar lugares de gestão.

Quanto ao perfil do empreendedor, o sr. Herman Lírio, 58 anos, engenheiro civil aposentado, optou por empreender como uma forma de preencher seu tempo livre, bem como complementar sua renda. As decisões do hotel são todas centralizadas em sua pessoa:

Eu tomo as decisões. Às vezes, consulto minha filha, mas a decisão final é minha. (ENTREVISTADO 1)

Quanto à sua percepção sobre inovação, o sr. Herman afirma considerar importante inovar, pois, segundo ele:

Os avanços tecnológicos estão cada vez mais rápidos e é preciso estar atento às mudanças. (ENTREVISTADO 1)

Porém, quando questionado sobre a inovação em serviços do dia-a-dia, o proprietário confessou nunca ter pensado sobre isso, e pareceu aberto a pequenas mudanças, desde que não implicassem em custos.

No estudo de Torres (2014), foi encontrado que uma das maiores barreiras para a inovação em pequenas empresas são os custos. Por vezes, pela forma amadora de gerir seu próprio negócio o empreendedor fixa-se em um pensamento de que tudo demanda de alto custo para inovar. Esse fato pode refletir a falta de interesse, em alguns casos, de pesquisar formas alternativas e criativas de inovação em serviços. No caso do Hotel Maresia, o seu proprietário não está disposto a investir altos valores em inovação, a não ser que o seu retorno seja consideravelmente alto e em médio prazo, dando preferência a utilizar capital próprio à empréstimos bancários.

O sr. Herman costuma se hospedar em outros hotéis para poder monitorar as práticas dos seus concorrentes, sendo essa a única forma intencional de monitoramento. No mais, afirmou buscar em sites e revistas, sempre que possível, as novidades no ramo. Sua filha também não possui nenhuma estratégia que vise principalmente buscar novidades sobre o ramo, mas comentou que gosta bastante de viajar, e que se em uma das viagens aparece alguma feira sobre turismo ou hotéis, eles costumam visitar.

Sobre ferramentas para sugestões (que podem auxiliar o processo de inovação), foi identificada no estabelecimento uma caixa de sugestões, ferramenta ultrapassada. Além dessa ferramenta, o proprietário informou que a maneira que eles colhem informações dos clientes, como sugestões, críticas, avaliações, é pela plataforma Booking, parceira da empresa. Quando questionado sobre o envolvimento dos funcionários no processo de ideias para a inovação ou sobre o interesse de saber a opinião dos funcionários sobre uma inovação que estará sendo implantada, o sr. Herman disse:

Não perguntamos nada. Eles não sabem opinar sobre as coisas que a gente quer colocar aqui. A gente que tem a visão geral, né? (ENTREVISTADO 1)

Dessa forma, fica claro que não há trabalho em equipe no quesito inovação, e que a postura gerencial é centralizadora quanto à tomada de decisão.

Quando perguntado sobre inovações feitas nos últimos dois anos, o proprietário afirma que modificou alguns processos na cozinha, devido a sugestões de clientes, estruturou o

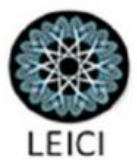


estacionamento, ampliou o número de quartos, construindo mais um andar, e equipou o quarto para deficientes físicos, devido à exigência da prefeitura.

\section{Caso 02: Pousada Do Lago}

O estabelecimento Pousada do Lago foi criada em 2008, com fins comerciais pelo sr. Delman Ismerim, após observar, por meio do seu antigo trabalho, a necessidade de pousadas na cidade de Aracaju. O sr. Delman possuía alguns apartamentos para aluguel e transformouos em pousada. A pousada do lago, também considerado empreendimento de pequeno porte, possui atualmente 25 unidades habitacionais, dividida nas categorias quartos casal standard, casal máster, duplo, triplo e quádruplo, equipados com ar condicionado, TV, frigobar, Wi-Fi gratuito e ducha quente. A pousada disponibiliza produtos de higiene para venda na recepção, dispõe de café da manhã incluso em todos os pacotes, possui um carro, um "Transit" para locação e aquecedor solar ecologicamente correto.

Hoje o estabelecimento conta com quatro funcionários, e de além da esposa, do filho e da irmã que o auxiliam informalmente na recepção. Devido à crise, o proprietário afirma que caiu cerca de $70 \%$ a ocupação em seu estabelecimento, como previu a HotelInvest - HVS (2014) um cenário turbulento a partir de 2015 para o setor hoteleiro. A maior parte dos clientes são turistas.

Esse ano caiu muito, esse ano caiu cerca de $70 \%$. De outubro até dezembro 'tá' cerca de $40 \%$ de ocupação. Dos clientes, $70 \%$ é turista, $30 \%$ é trabalho. (ENTREVISTADO 2)

O sr. Delman declarou que não possui parceria, apenas com a Booking, e considera como pontos fortes da pousada a sua localização, a quantidade de quartos e o espaço do estabelecimento, e identifica como ponto fraco o fato de não possuir piscina, mas que não seria exatamente um ponto fraco, mas uma oportunidade de melhorar.

Quanto a busca por atualização no ramo hoteleiro, o empresário disse que costuma estar atualizado por meio de conhecidos no ramo, mas não participa de cursos de gestão ou nada relativo ao ramo hoteleiro. Quando percebe algo que foi implantado por outra pousada ou percebe uma tendência, busca trazê-la para o negócio. Esse comportamento confirma o estudo de Mattson, Sundbo e Jensen (2005), que sugere que as inovações no ramo turístico são de fácil imitação, e por isso frágeis. Quando questionados sobre os concorrentes, o sr. Delman disse que não vê os outros estabelecimentos hoteleiros como concorrentes, mas parceiros. Assim, quando a pousada dele está $100 \%$ ocupada, ele indica para outras, e afirma que o mesmo acontece com os seus "concorrentes".

Eu não chamo concorrentes. Eu costumo chamar de parceiros, porque na verdade somos parceiros. Quando aqui 'tá' lotado eu indico pra outra pousada, até pelo bemestar do cliente. Às vezes o cliente vem de outro estado, não conhece nada. (ENTREVISTADO 2)

O empreendedor Delman Ismerim, 53 anos, é natural de Santa Catarina e possui o nível médio completo. Antes de se tornar empresário, atuava como representante da PVCerca e possuía apartamentos para veraneio que eram alugados. Todo capital aplicado para iniciar as atividades como uma empresa registrada foram $100 \%$ próprio.

Quando questionado sobre a tomada de decisão, o sr. Delman afirmou que ele toma todas as decisões, sem consultar os funcionários, mas acredita ser aberto às sugestões, pois

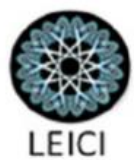


são construtivas e que algumas delas já foram implantadas, porém não citou nenhuma. Essas sugestões são feitas pessoalmente na recepção ou no site da pousada ou no Booking, não possuindo nenhuma outra ferramenta específica com essa finalidade.

O proprietário afirma que nos últimos dois anos trouxe como inovação: aquecedor solar, trocou os ar-condicionados antigos em todos os quartos para o modelo Split. Afirma também que é preciso inovar, pois se o cliente vê que a qualidade está caindo por falta de inovação, ele passa a não frequentar mais o estabelecimento. Acredita que o próximo passo para inovar seja a piscina e a energia solar, mas que dependeria de incentivo do governo para essa última.

\section{Caso 03: Pousada Águas Cristalinas}

A Pousada Águas Cristalinas foi fundada em 1999, também com fins comerciais, pela senhora Rita de Lourdes. O estabelecimento possui 33 unidades habitacionais, divididos em quartos que vão de duplo a sêxtuplo, com frigobar, banheiro privativo, ar-condicionado e TV; refeitório, cozinha (café da manhã) e estacionamento privativo.

Percebe-se que não há estrutura organizacional organizada, sendo também seu proprietário o gerente administrativo-financeiro e todos os outros empregados estando abaixo dessa posição e em um mesmo nível hierárquico. O estabelecimento possui 03 funcionários, além da proprietária e sua família que também trabalham informalmente em todas as áreas em que sejam necessárias. Isso corrobora com o estudo de Moraes (2004), que afirma que a empresa familiar se apresenta de forma desorganizada quanto a definição de cargos responsabilidades, e autoritária e centralizada no quesito tomada de decisão, pode se valer do trabalho em equipe para resolução de questões.

Aqui tem a copeira, a cozinheira, tem eu também que lavo, passo, todo mundo aqui faz tudo. Aqui não tem essa não. (ENTREVISTADA 3)

A empresária também afirmou que no ano corrente houve uma baixa drástica na ocupação das unidades habitacionais, chegando a uma média de $20 \%$ de ocupação nos quartos, conforme previu a HotelInvest (2014), sendo seus principais clientes turistas. Quanto aos parceiros, citou apenas a plataforma Booking. Considerou como ponto forte a localização, próximo à Orla de Atalaia, porém disse não enxergar nenhum ponto negativo.

Quanto à tomada de decisão, acontece de forma centralizada, sendo apenas a proprietária detentora do poder de decisão, não consultando nenhum empregado. Porém, afirmou que está aberto a sugestões e possui uma "caixa de sugestões" para a manifestação dos clientes. A proprietária informou que já fez melhorias no estabelecimento, como por exemplo o sinal de internet, por sugestão de clientes.

A proprietária comentou que a maneira que tem de buscar estar informada das novidades no ramo hoteleiro é por meio de sites, apenas. Para melhoria do atendimento, informou que investiu em cursos no SENAC e SEBRAE para alguns funcionários. Quanto a percepção de concorrência, a proprietária também acredita que trabalha com parceiros, não concorrentes. Quando existe uma alta demanda de clientes em determinada estação e as unidades habitacionais lotam, a pousada indica outros estabelecimentos que possuam vagas disponíveis.

O que tiver que ser meu, vai ser meu. Não existe concorrente. (ENTREVISTADA 3)

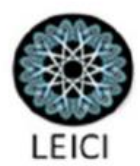


A reforma nos apartamentos (e o aumento do número dos quartos) e cobertura do estacionamento, foram melhorias feitas nos últimos dois anos. Outra pequena melhoria que a proprietária cita é a instalação no novo modelo de tomada nos quartos; a gestão também deu início à troca de todos os ar-condicionados dos quartos.

\section{Considerações finais}

O estudo se propôs a identificar a percepção dos pequenos empreendedores sobre a inserção da ferramenta da inovação em seu empreendimento. Por meio de um estudo de múltiplos casos, buscou-se identificar qual o estilo de liderança do empreendedor, sua percepção sobre a importância do papel da inovação para a empresa e apontar as inovações realizadas no empreendimento nos últimos dois anos.

De acordo com o discurso dos entrevistados, identificou-se uma postura centralizadora quanto à tomada de decisão. Em nenhum dos casos analisados foi possível perceber um espaço onde os funcionários da empresa tivessem alguma participação na inserção de inovação ou quaisquer mudanças dentro da organização. Essa postura é típica de pequenos empreendimentos familiares, em que o próprio dono detém o poder. Segundo De Vries (1993), uma das desvantagens das empresas familiares são as regras autoritárias e paternalistas.

Foi possível perceber também que o discurso geral entre os empreendedores aponta a inovação como uma ferramenta importante, principalmente para manter clientes, conforme sugerido pela literatura, porém, é perceptível alguns desvios nesse discurso, principalmente quando a inovação se relaciona a custos financeiros. Percebeu-se em uma das entrevistas que nem sempre o empreendedor estará disposto a investir em inovação, se isso não lhe retornar em benefícios a curto prazo. Outro comportamento que enfraquece o discurso da importância da inovação diz respeito a maneira como uma das empreendedoras afirma que não há pontos fracos em seu empreendimento. Foram identificadas algumas inovações em todos os empreendimentos estudados, alguns em níveis mais básicos, outros mais relevantes.

A conclusão que se chega nesse estudo é de que, em teoria, os empreendedores entendem como importante a constante mudança no sentido de inovar, e de principalmente estar atentos aos comentários de clientes nesse processo, que se torna um fator crítico para essa mudança, porém, na prática, existem fatores em seu discurso que enfraquecem essa teoria. É necessário que o próprio empreendedor se convença de que é necessário mudar, pois é ele quem detém esse poder dentro da organização. Esse estudo encontra limitações no que diz respeito ao número da amostra e sugere que a pesquisa seja replicada em outros setores, combinada a uma pesquisa quantitativa para melhor sustentação. 


\section{Referencial Teórico}

ALVES, S. Estratégias de Inovação em Mercados Maduros: Um olhar a partir do Segmento de Serviços de Hotelaria. In: SEMINÁRIO DA ASSOCIAÇÃO NACIONAL PESQUISA E PÓS-GRADUAÇÃo EM TURISMO, 2011, Balneário Camboriú/SC, Brasil, Anais... Balneário Camboriú/SC, 2011.

BERG, B. L. Qualitative Research Methods for the Social Sciences. 4. ed. Needham Heights: Allyn \& Bacon, 2001.

BESSANT, J.; TIDD, J. Inovação e Empreendedorismo. Porto Alegre: Bookman, 2009.

BRASIL. Ministério do Turismo. Disponível em: <http://www.embratur.gov.br/piembraturnew/opencms/salaImprensa/artigos/arquivos/Turismo_contribui_com_9_do_PIB_mundial.ht ml>. BRASIL. Ministério do Turismo. 2015. Acesso em: 12 dez. 2016.

BRUYAT, C.; JULIEN, P.-A. Defining the field of research in entrepreneurship. Journal of Business Venturing, v. 16, p. 165-180, New York: Elsevier Science Inc., 2000.

CARDOSO, C.S.; BATISTA ,S.G. Inovação da oferta turística com base nos valores locais: um estudo do Geoparque Seridó, RN, Brasil. Caderno Virtual de Turismo. Rio de Janeiro, v. 13, n. 2., p.150-161, ago. 2013.

CHUA, J. H.; CHRISMAN, J. J.;SHARMA, P. Defining the family business by behaviour. Entrepreneurship Theory and Practice 1999.

CLASSEN, N.; CARREE, M.; GILS, A.; PETERS, B. Innovation in family and non-family SMEs: An exploratory analysis. Small Business Economics, 2014.

DAMANPOUR, F.; SCHNEIDER, M. Phases of the adoption of innovation in organizations: effects of environment, organization and top managers. British Jornal of Management, 2006.

DE MASSIS, A.; FRATTINI, F.; PIZZURNO, E.; CASSIA, L. Product innovation in family Vs. Nonfamily firms: An exploratory analysis. Journal of Small Business Management, 2015.

DE VRIES, K. The dynamics of family controlled firms: the good and the bad news. Organizational Dynamics. Amsterdam, v. 21, n. 3, p. 59-71, 1993.

JOÃO, B. N.; CLARO, J. A. C. D. S.; DIAS, A. H.; SARMENTO, M. B. C. P. Inovação de valor: o caso Citizenm Hotels. Turismo: Visão e Ação, v. 13, n. 3, art. 2, p. 299-310, 2011.

LARA DE OLIVEIRA, J.; ALBUQUERQUE, A. L.; PEREIRA, R. D. Governança, Sucessão e Profissionalização em uma Empresa Familiar: (re)arranjando o lugar da família multigeracional. Revista Brasileira de Gestão de Negócios, v. 14, n. 43, p. 176-192, 2012.

LAVILLE, C.; DIONNE, J. A construção do saber: manual de metodologia da pesquisa em ciências humanas. Porto Alegre: ARTMED, 1999.
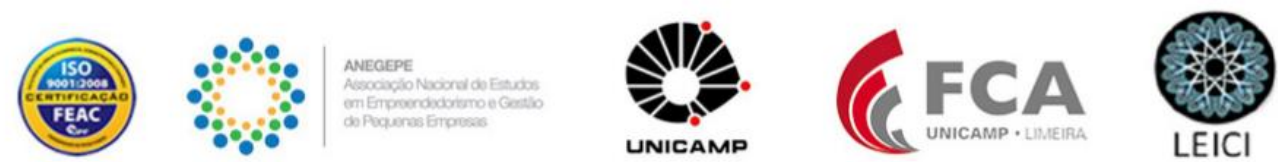
MANUAL DE OSLO 2004. Proposta de diretrizes para coleta e interpretação de dados sobre inovação tecnológica. Organização para Cooperação Econômica e Desenvolvimento, Departamento Estatísticoda Comunidade Européia e FINEP — Financiadora de Estudos e Projetos. Disponível em: http://www.finep.gov.br/imprensa/sala_imprensa/manual_de_oslo.pdf $>$. Acesso em: 02 jan. 2017.

MATTSSON, J., SUNDBO, J.; JENSEN, C. F. Innovation systems in tourism: the roles of attractors and scene-takers. Industry and Innovation, v.12, n. 3,p. 357, 2005.

MATZLER, K.; VEIDER, V.; HAUTZ, J.; STADLER, C. The impact of family ownership, management, and governance on innovation. Journal of Product Innovation Management, 2015.

MORAIS, João Marcelo. Estrutura organizacional na empresa familiar - Estilos gerenciais e satisfação dos funcionários. 2004. 220 f. Dissertação (Mestrado em Gestão e Desenvolvimento Regional) - Departamento de Economia, Contabilidade e Administração, Universidade de Taubaté, Taubaté, Brasil.

NEUMAN, W.L. Social Research Methods: Qualitative and Quantitative Approaches. 3 ed. USA: Allyn \& Bacon, 1997.

NÓBREGA, G. J., \& Hoffmann, V. E. Family business and the creation of Entrepreneurship through their internal resources. RPCA - Revista Pensamento Contemporâneo em Administração, n.92-105, 2014.

PADILLA-MELÉNDEZ, A.; DIEGUEZ-SOTO, J.; MORENO, A. G. Pesquisa empírica sobre Inovação na Empresa Familiar: revisão de literatura e proposta de estrutura integrativa. Revista Brasileira de Gestão de Negócios, v. 17, n. 56, p. 1064-1089, 2015.

PAVITT, K. Sectoral patterns of technical change: towards a taxonomy and a theory. Research Policy, v.13, 1984, p. 343-73.

PETROCCHI, M. Hotelaria: planejamento e gestão. São Paulo: Futura, 2002.

Turismo, planejamento e gestão. 2.ed.-São Paulo: Pearson Prentice Hall, 2009.

RUSCHMANN, D.; SOLHA, K. T. Turismo: uma visão empresarial. Barueri: Manole, 2003.

SACRAMENTO,P; TEIXEIRA, R. Implementação de ações inovadoras e empreendedorismo: Estudo de múltiplos casos em empresas hoteleiras de pequeno porte. Caderno Virtual de Turismo. Rio de Janeiro, v. 14 n. 2., p.183-203, ago. 2014.

SALES, M. D.; SANCHES, C. Tipologia de cultura organizacional empreendedora: proposta de processo de taxonomia da cultura organizacional de uma empresa com base na orientação empreendedora dos líderes. Revista de Tecnologia Aplicada, v. 2, n. 1, p. 28-50, 2013 
SMITH, M.; BUSI, M.; BALL, P.; VAN DER MEER, R. Factors influencing an organisation's ability to manage innovation: a structured literature review and conceptual model. International Journal of Innovation Management, v.12, p 655-676, 20086.

TORRES, L. F. P.; SILVA, F. C. L. A inovação nas empresas de Caruaru-PE. International Journal of Innovation, v. 2, n. 2, p. 132-159, 2014.

UNWTO. Tourism Highlights. Ed. 2016. Disponível em: 〈http://www.unwto.org>. Acesso em 04. Mar. 2016.

YU, A. S. O.; KLEMENT, C. F. F. Inovação na indústria hoteleira: complementação entre inovações tecnológicas e inovações baseadas em serviços. Observatório de Inovação do Turismo, v. 1, n. 3, Dezembro, p. 1-17. 2006. 